Viso - Cadernos de estética aplicada Revista eletrônica de estética

ISSN 1981-4062

$N^{\circ} 11$, jan-jun/2012

http://www.revistaviso.com.br/

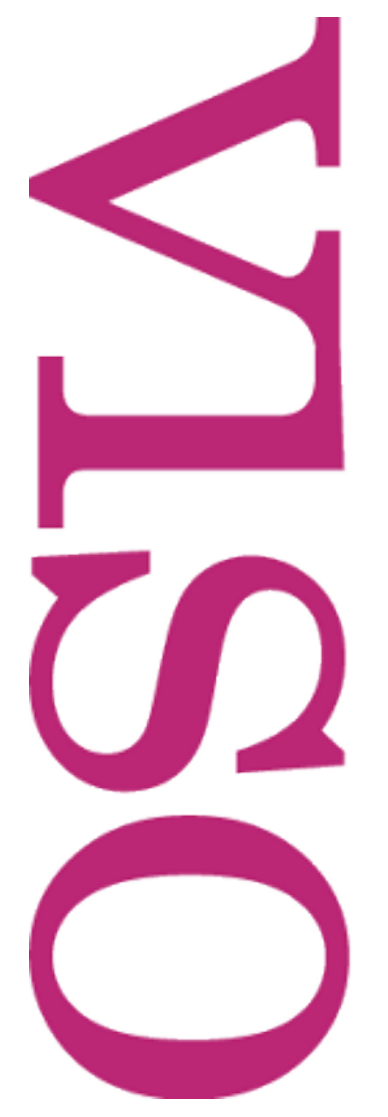

\title{
Do tradicional ao indiciário, e depois: Uma narrativa contemporânea brasileira Bernardo Oliveira
}




\section{RESUMO}

Do tradicional ao indiciário, e depois: Uma narrativa contemporânea brasileira

Partindo do conceito de "narrativa indiciária", inspirada no de "paradigma indiciário", de Carlo Ginzburg, e em observações de Walter Benjamin sobre narrativa, este artigo procura caracterizar um gênero moderno, o romance policial, e localizar, com referência a este, um exemplo contemporâneo e brasileiro, o romance Mongólia, de Bernardo Carvalho.

Palavras-chave: narrativa - Brasil - contemporâneo

\section{ABSTRACT}

From Traditional to Indiciary, and Beyond: A Brazilian Contemporary Narrative

Based on the concept of "indiciary narrative", inspired by the notion of "indiciary paradigm" by Carlo Ginzburg, and by some Walter Benjamin's remarks about narrative, this article seeks to characterize a modern genre, the detective story, and locate, with a reference to it, a contemporary example of Brazilian novel, Bernardo Carvalho's Mongolia.

Keywords: narrative - Brazil - contemporary 
OLIVEIRA, B. "Do tradicional ao indiciário, e depois: Uma narrativa contemporânea brasileira". In: Viso: Cadernos de estética aplicada, v. VI, n. 11 (jan-jun/2012), pp. 202-210.

DOI: $10.22409 / 1981-4062 / v 11 i / 133$

Aprovado: 10.04.2012. Publicado: 07.09.2012.

(c) 2012 Bernardo Oliveira. Esse documento é distribuído nos termos da licença Creative Commons Atribuição-NãoComercial 4.0 Internacional (CC-BY-NC), que permite, exceto para fins comerciais, copiar e redistribuir o material em qualquer formato ou meio, bem como remixá-lo, transformá-lo ou criar a partir dele, desde que seja dado o devido crédito e indicada a licença sob a qual ele foi originalmente publicado.

Licença: http://creativecommons.org/licenses/by-nc/4.0/deed.pt_BR

Accepted: 10.04.2012. Published: 07.09.2012.

(C) 2012 Bernardo Oliveira. This document is distributed under the terms of a Creative Commons Attribution-NonCommercial 4.0 International license (CC-BY-NC) which allows, except for commercial purposes, to copy and redistribute the material in any medium or format and to remix, transform, and build upon the material, provided the original work is properly cited and states its license.

License: http://creativecommons.org/licenses/by-nc/4.0/ 
Carlo Ginzburg, em seu célebre ensaio sobre o método indiciário, de passagem elabora uma hipótese para o surgimento do discurso narrativo. Para tanto cria a imagem de um arcaico caçador-narrador que relata, para efeitos práticos, o que pode ter acontecido. Este saber, indicado por Ginzburg como o mais arcaico que há, consiste na "capacidade de, a partir de dados aparentemente negligenciáveis, remontar a uma realidade complexa não experimentável diretamente. Pode-se acrescentar que esses dados são sempre dispostos pelo observador de modo tal a dar lugar a uma seqüência narrativa, cuja formulação mais simples poderia ser 'alguém passou por lá'.' ${ }^{1}$

Esta "realidade complexa não experimentável diretamente" é constituída pela capacidade do caçador-narrador de configurar: a narrativa ordena e relaciona ações como partes de um todo de caráter temporal. O "alguém passou por lá" é composto por diversas partes dispersas, impressas aqui e ali como vestígios de um percurso. O caçador é capaz de segui-las porque vai ao mesmo tempo elaborando mentalmente uma ordenação em que o "e então", "e depois" se encadeiam na busca por um final. Sucessão e perenidade, dois tempos diferentes, se articulam quando se chega a um fim. O "alguém passou por lá", que auxilia o caçador, de início é apenas uma história em aberto. Neste caso, o fim prático e o fim da história coincidem. Seu fechamento dará ensejo a que o caçador retome discursivamente todo o processo. O êxito ou fracasso do caçador que compôs uma história e foi averiguar se procedia pode ser retomado diante de ouvintes. Estes supõem que o caçador-narrador conta aquilo que experimentou diretamente, aquilo que ele sabe. Lembremos que narrator provém etimologicamente de gnarus, aquele que sabe, o oposto de ignarus. Esta experiência, baseada inicialmente em leitura de sinais impressos pelos animais, torna-se, com o tempo, uma herança narrativa, transmitida oralmente: "gerações e gerações de caçadores enriqueceram e transmitiram esse patrimônio cognoscitivo". 2 Lembremos que este narrador caçador é uma hipótese ilustrativa formulada por Ginzburg, e que a narrativa indiciária mais antiga aludida pelo autor do ensaio é o conto "Zadig", de Voltaire. Podemos de nossa parte conjecturar em que consistiria este processo de enriquecimento e de transmissão através de gerações de caçadores, supondo que ouvir tais relatos ajudava a dar forma à caçada, moldando expectativas e fornecendo modelos de continuidade para cada situação vivida. Estas, por sua vez, traziam novos elementos para o patrimônio narrativo, ou seja, uma dinâmica de realimentação entre o viver e o narrar a caçada, e podemos até chegar a nos perguntar se até mesmo este hipotético primeiro narrador não teria de ser guiado por algum modelo narrativo prévio que the possibilitasse ver a caçada como uma pré-narrativa.

Isto nos leva a uma outra teorização, ainda mais célebre, a respeito da história do contar. Walter Benjamin nos fala de uma prática arcaica da narrativa, onde o contar e o recontar são inseparáveis: "Sabia-se exatamente o significado da experiência: ela sempre fora comunicada aos jovens. De forma concisa, com a autoridade da velhice, em provérbios; de forma prolixa, com a sua loquacidade, em histórias; muitas vezes como narrativas de países longínquos, diante da lareira, contadas a pais e netos". ${ }^{3}$ O narrador, neste contexto onde predomina a transmissão de saberes, parte sempre da retomada de 
alguma narrativa já ouvida de outrem: "Contar histórias sempre foi a arte de contá-las de novo". ${ }^{4} \mathrm{O}$ contador de histórias de que fala Benjamin "[...] pode recorrer ao acervo de toda uma vida (uma vida que não inclui apenas a própria experiência, mas em grande parte a experiência alheia. O narrador assimila à sua substância mais íntima aquilo que sabe por ouvir dizer)". ${ }^{5}$ Transmitir uma experiência implica ter um saber valioso a transmitir, alguma coisa cujo sentido às vezes não é descoberto de imediato por quem a recebe. O lugar emblemático da narrativa não é mais a floresta de sinais, por onde se aventura o primeiro narrador e também primeiro leitor em busca da história recente de sua caça, mas sim o ateliê do artesão, onde se fia ou tece enquanto se escutam e recontam histórias. A distensão psíquica do artesanato, isto é, de um trabalho também baseado na transmissão e no lento aperfeiçoamento, substitui a tensa espera do caçador. No entanto, o ateliê do artesão é o cruzamento de dois "tipos arcaicos" de narrador, e aí estamos muito próximos da tese de Ginzburg:

'quem viaja tem muito a contar', diz o povo, e com isso imagina o narrador como alguém que vem de longe. Mas também escutamos com prazer o homem que ganhou honestamente sua vida sem sair do seu país e que conhece suas histórias e tradições. Se quisermos concretizar esses dois tipos através dos seus representantes arcaicos, podemos dizer que um é exemplificado pelo camponês sedentário, e outro pelo marinheiro comerciante. ${ }^{6}$

O "sistema corporativo medieval" teria unido estes dois tipos arcaicos na figura do "aprendiz ambulante" que se torna um trabalhador sedentário quando finalmente se instala em um lugar. Tal como para Ginzburg, Benjamin assinala que o ato de narrar recebe sua motivação e sua forma inicial de um ofício e de uma situação prática muito distantes do ofício do escritor, e que viver e narrar se retroalimentam. Quem viaja passa por situações exemplares que são dignas de serem lembradas, ou ouve histórias de quem está num lugar há várias gerações e que recolheu o que ouviu contar. Estes dois tipos se interpenetram na figura do contador de histórias benjaminiano.

A escuta e a memorização das histórias fazem parte do processo denominado tradição, onde "...a relação ingênua entre o ouvinte e o narrador é dominada pelo interesse em conservar o que foi narrado". ${ }^{7}$ Conjecturamos aqui também se o interesse em conservar o narrado, para recontá-lo, não fornece um modelo narrativo onde encaixar os acontecimentos da vida, afinal, "onde há experiência no sentido estrito do termo, entram em conjunção, na memória, certos conteúdos do passado individual com outros do passado coletivo". ${ }^{8}$ O passado coletivo é o passado narrado. Não seria este "entrar em conjunção, na memória”, uma explícita modelagem desta pela forma narrativa?

Nas considerações de Walter Benjamin, a história do contador de histórias é envolvida pela história da experiência. Conservar, transmitir, retomar, interpretar a herança são movimentos da experiência, que se enfraquecem durante o processo que Benjamin chama de crise da tradição, o período da Modernidade industrial e da informação jornalística. Os contos de Poe são uma peça de suma importância nos textos 
benjaminianos sobre Baudelaire e a moderna crise da experiência em seu sentido tradicional. Mas se visitamos o conto que geralmente é tomado como marco inicial da literatura policial, "Os crimes da Rua Morgue", encontramos outros elementos para entender o porquê da importância da vertente indiciária deste autor para o tema da crise da experiência em sua forma pré-moderna. O narrador do conto diz que "observar atentamente equivale a recordar com clareza". ${ }^{9}$ Para compreendermos toda a originalidade desta diretriz, devemos destacá-la sobre o pano de fundo da experiência tradicional e sua memória coletiva e narrativa. Em "Os crimes da Rua Morgue", a personagem detetive precisa compor uma imagem com início, meio e fim dos acontecimentos que culminaram num duplo assassinato, e cujos indícios se encontram dispersos e ocultos no local onde foram encontrados os cadáveres. Estes, obviamente, representam a mais extrema incapacidade de contar o que quer que seja. As únicas testemunhas vivas do acontecimento não viram a cena, mas apenas escutaram gritos e diferentes vozes, que tomam invariavelmente por uma língua estrangeira que não conhecem. Os depoimentos são confusos e a polícia resolve responsabilizar alguém que não teve qualquer participação. A estrutura básica do conto se repetirá centenas, milhares de vezes através de uma literatura que continua forte até hoje: o personagem detetive chega a um lugar onde ninguém pode ou deseja contar o que aconteceu. $\mathrm{O}$ responsável pelos acontecimentos desapareceu ou está disfarçado. As identidades são no mínimo dúbias, precisam ser estabelecidas. Depoimentos falsos, intencionais ou não, são comuns e só vêm corroborar a regra que rege este novo universo: ninguém conta nada, e o personagem principal, o detetive, ao contrário de receber narrativas como herança, terá de tecer a história do que aconteceu a contrapelo desta situação.

$\mathrm{Na}$ falta de histórias ouvidas, constrói-se uma com o que se vê. A nova narrativa indiciária reatualiza, no espaço urbano das novas metrópoles do séc. XIX, a situação que, seguindo a proposta de Carlo Ginzburg, deu origem ao ato de narrar. Na falta de histórias que precedam o narrador, este se vê obrigado a construir uma história. Mas não voltamos ao hipotético caçador: a situação é outra, e leva em conta de algum modo a história de que decorre. Dentro da forma do novo indiciário está inscrita a longa história da própria forma narrativa. A forma narrativa é uma memória de seu próprio desenvolvimento.

A narrativa denominada policial não é a única a se reapropriar do modo indiciário. $O$ próprio Carlo Ginzburg, num rápido comentário, estende a toda literatura romanesca o papel de concentrar o saber indiciário, até mesmo uma obra como a de Proust. ${ }^{10} \mathrm{~A}$ leitura de Ginzburg acentua o papel desempenhado pela tradição do romance como refúgio de um tipo de saber não dominante na era das ciências modernas. Neste ponto a influência de Foucault é notória, mas não podemos desenvolver isso. O que nos importa aqui é que tanto Benjamin quanto Ginzburg oferecem uma interpretação unificante das necessidades que geraram a moderna narrativa indiciária. Para Ginzburg, a ficção cumpre o papel de fornecer um refúgio para um modo de conhecimento que visa atingir o particular, e não o universal, Para Benjamin, a função dela é mostrar o desnorteamento 
do homem moderno, encapsulado em suas vivências rigorosamente individuais e sua fragilidade diante da técnica e da política. O motor do ofício de narrar não seria mais o de transmitir a segurança do passado, mas manter diante de nós a pobreza de experiência e de sentido. Esta atitude seria mais verdadeira do que qualquer modalidade de escamoteamento da situação de indigência. $O$ detetive Dupin e o narrador proustiano, cada um à sua maneira, representam apostas otimistas na força da narrativa para sobreviver numa situação onde não se recebe nem se dá nenhum conselho ou herança. Vejamos, através de um exemplo muito recente, se podemos começar a descrever o modo como a narrativa vê a si mesma.

O romance Mongólia, de Bernardo Carvalho, é uma oportunidade, na literatura de ficção brasileira recente, de discutir o nosso ponto central. Neste romance, a alternativa já não é tanto ou a segurança da tradição, ou o desnorteamento da vivência moderna. Talvez estejamos diante de um exemplo brasileiro em que a reflexividade da forma literária se concentra agora na consciência não tanto de que o mundo pós-tradicional seja carente de um sentido, mas sim de que todos os sentidos que ele provisoriamente possui somos nós que conferimos, através de algum modelo herdado, principalmente modelos narrativos. O norte da arte de narrar é a própria história da narrativa. Bernardo Carvalho cria um núcleo de personagens que pratica a escrita de diários e/ou cartas, cujo conteúdo principal é o relato de viajante, que exerce a leitura e a exegese de textos recebidos, que colhe depoimentos orais e compara lugares descritos com lugares vistos, que coleciona indícios para cobrir lacunas nos textos, compondo afinal um vasto mosaico de atitudes que fazem parte da longa história do narrar.

A personagem narradora principal é um diplomata aposentado, depositário das anotações em forma de diário ou de longa carta com destinatário incerto que um outro diplomata deixara sob sua guarda quando haviam servido ambos na embaixada brasileira de Pequim, alguns anos antes. O texto do narrador procura compreender, entremeando com a citação de longas passagens da carta/diário, uma missão que o outro havia desempenhado por ordens suas, e que consistia em descobrir sinais do paradeiro de um fotógrafo brasileiro, filho de uma personalidade influente, desaparecido havia meses na Mongólia, aonde tinha ido fazer uma matéria para uma revista de turismo. O trabalho do narrador é compreender o percurso de seu subordinado de outrora, que lhe legou uma pasta com suas anotações feitas durante a missão, que visava reconstituir os passos do fotógrafo, o qual, porém, também deixara dois cadernos de anotações de viagem, cada um de posse de um dos dois guias de que se serviu em dois trajetos diferentes pelo interior do país que dá nome ao livro. O diplomata detetive enviado à Mongólia pelo narrador, a quem este chama simplesmente de "o Ocidental", "teria de agir como investigador sob o disfarce de simples turista". ${ }^{11}$ Este, ao chegar a Ulaanbataar, "seguiu noite adentro pelas páginas do diário escrito um ano antes, em busca de pistas". ${ }^{12}$ Somos levados através de uma sobreposição de diários, em que os relatos do primeiro viajante são incluídos nos do segundo, que conta, por sua vez, a sua própria viagem investigativa guiada pelo texto do primeiro. A situação "original", a do 
fotógrafo, se desdobra na do seu investigador, mais tarde, e, finalmente, na do personagem que se apresenta como o compositor daquela memória em três níveis. Este último se apresenta como alguém que postergou até a última hora um acalentado projeto de ser escritor, o que não deixa de ter um eco proustiano. A tríade composta pelo "desaparecido", pelo "Ocidental" e pelo diplomata aposentado finalmente escritor tece dentro do texto uma pequena comunidade de memórias, uma cadeia de relatos de viajante, na qual os textos recebidos como herança são continuados por quem os recebe. A leitura e a exegese são motivadas pelo desejo de verdade: o diplomata aposentado tenta compreender o seu colega, que acabara de morrer, e este, por sua vez, tentava compreender o fotógrafo desaparecido. A expectativa do leitor, criado na tradição indiciária, é a de que tudo leva a algum nível de solução para os mistérios representados por cada investigado. Ao fim, o diplomata narrador não deixa a história em aberto, pois lega ao leitor uma solução do mistério, mesmo que não tenha ocorrido nenhum crime, tal como nas fórmulas da tradição do indiciário mais difundido, a do romance policial, mostrando bem que conhece seu leitor e suas expectativas.

O tom predominante de ambos o diários, tanto o do "desaparecido" quanto o do "Ocidental", é o dos relatos de viagem, muito comuns nos sécs. XVIII e XIX. No ensaio benjaminiano sobre o contador de histórias, vimos, o relato de quem vem de longe se confunde com a noção de experiência, Erfahrung. Mas aqui o olhar não é o de quem deseja conservar uma realidade original e exemplar. Os comportamentos e instituições dos nativos estão sob a suspeita de fraude, é constante a desconfiança quanto à autenticidade e sinceridade dos ritos e das informações dadas pelos guias. Estes guias, procurados pelo diplomata-detetive, são uma espécie de braço artesanal da indústria do turismo, acostumados a vender a imagem de uma Mongólia pretensamente tradicional. Como dublês de típicas testemunhas em histórias policiais e de guardiões da tradição, seus relatos não são dignos de confiança. "Ninguém sabe nada de lugar nenhum", diz o Ocidental em seu texto. A busca por pistas ou relatos que levem a decifrar o paradeiro do fotógrafo é complicada pelo nomadismo dos habitantes da zona rural do país. A própria paisagem resiste a ser nomeada: "É como se as construções também fossem nômades e se movimentassem pelas planícies para completar, na Mongólia, lugares diferentes têm o mesmo nome, como se o próprio terreno fosse movediço". ${ }^{13}$

Relatado deste modo, tudo leva a crer que, no romance de Carvalho, estamos no terreno de Poe e da experiência urbana do séc. XIX, em uma versão radicalizada, não fosse o discreto porém insistente tom de paródia que atravessa todo o livro. Paródia de romance policial, de experiência de viajante, de relato etnográfico sobre o encontro com uma cultura tradicional. Tudo leva a minar a expectativa realista de que alguém está contando uma história tal como realmente aconteceu. Ao contrário, o confronto entre as histórias urdidas na cabeça das personagens e a averiguação a respeito da sua veracidade leva a mais histórias e ao surgimento de mais personagens cuja identidade é mal estabelecida, e a versões e fantasias impossíveis de averiguar. É explícita a hipótese de que os dois viajantes, cada um a seu modo, teriam criado histórias com suas perguntas, com sua 
insistência em saber de coisas que ninguém mais lembrava: o fotógrafo em sua busca motivada a princípio pela curiosidade a respeito do culto a uma estranha divindade e o diplomata detetive procurando entender o que teria levado o primeiro a se embrenhar sem volta numa segunda viagem. A certa altura, o guia diz, a respeito do primeiro, que "era ele quem criava a história com as suas perguntas. A história estava na cabeça dele". ${ }^{14}$ No entanto, parece não haver outra saída senão insistir na composição deste tecido chamado história. Como diz o diário do ocidental, "não dá para saber quando e onde a história começa. Uma coisa leva a outra, e a coerência parece só ter efeito retroativo"15, o que descreve com perfeição o ofício da personagem do narrador deste romance, e um indicativo da consciência que a narrativa tem de si nos dias de hoje.

* Bernardo Oliveira é professor associado do Departamento de Filosofia da UFF.

${ }^{1}$ GINZBURG, C. "Sinais: raízes de um paradigma indiciário" In: Mitos, emblemas e sinais. São Paulo: Cia das Letras, 1998, p. 152.

2 Ibidem, p. 151.

${ }^{3}$ BENJAMIN, W. "Experiência e pobreza". In: Obras escolhidas I, p. 114.

${ }^{4}$ Idem. "O narrador. Considerações sobre a obra de Nikolai Leskov". In: Obras escolhidas I, p. 205.

${ }^{5}$ Ibidem, p. 221.

${ }^{6}$ BENJAMIN, W. "O narrador". Op. cit., pp. 198-199.

${ }^{7}$ Ibidem, p. 210.

${ }^{8}$ BENJAMIN, W. "Sobre alguns temas em Baudelaire". In: Obras escolhidas III. São Paulo: Brasiliense, 1994, pp. 106-107.

${ }^{9}$ POE, E. A.' Ficção completa, poesia \& ensaios. Rio de Janeiro: Nova Aguilar, 1986, p. 66.

${ }^{10}$ GINZBURG, C. Op. cit., p. 178. A respeito do romance em geral ele diz que "[...] é justamente graças à literatura de imaginação que o paradigma indiciário conheceu nessa época [o Séc. XIX] um novo, e inesperado, destino" (p. 168).

${ }^{11}$ CARVALHO, B. Mongólia. São Paulo: Cia das Letras, 2003, p. 14.

12 Ibidem, p. 38.

${ }^{13}$ Ibidem, p. 134.

${ }^{14}$ Ibidem, p.169.

${ }^{15}$ Ibidem, p. 132 